\title{
Trends in Hybrid Nanocoatings ${ }^{\dagger}$
}

\author{
Cristian Petcu 1,*, Ioana Cătălina Gîfu 1 , Cristina Scomoroscenco ${ }^{1}$, Cătălin Ionuț Mihăescu 1, \\ Claudia Mihaela Ninciuleanu ${ }^{1}$, Cristina Lavinia Nistor ${ }^{1}$, Raluca Ianchiş ${ }^{1}$, Elvira Alexandrescu ${ }^{1}$, \\ Adina Răducan ${ }^{2}$, Maria Marinescu ${ }^{2}$ and Ludmila Otilia Cinteza ${ }^{2}$
}

1 Polymers Department, National Institute for Research \& Development in Chemistry and PetrochemistryICECHIM, 202 Spl. Independentei, 060021 Bucharest, Romania; vacaresteanu_catalina@yahoo.com (I.C.G.); scomoroscencocristina@gmail.com (C.S.); mihaescu_catalin96@yahoo.com (C.I.M.);

claudia.ninciuleanu@yahoo.com (C.M.N.); lc_nistor@yahoo.com (C.L.N.); ralumoc@yahoo.com (R.I.); elviraalexandrescu@yahoo.com (E.A.)

2 Physical Chemistry Department, University of Bucharest, 4-12 Regina Elisabeta Blv., 030018 Bucharest, Romania; adina.raducan@g.unibuc.ro (A.R.); maria7marinescu@yahoo.com (M.M.); ocinteza@gw-chimie.math.unubuc.ro (L.O.C.)

* Correspondence: cristian.petcu@icechim-pd.ro; Tel.: +40-21-316-3093

+ Presented at the 15th International Symposium "Priorities of Chemistry for a Sustainable Development" PRIOCHEM, Bucharest, Romania, 30 October-1 November 2019.

Published: 15 October 2019

Keywords: coatings; metallic nanoparticles; inorganic nanoparticles; antimicrobial; environmentally friendly synthesis; plant extract

The aim of the present work was to prepare intelligent materials for coatings with advanced protection properties against development of biofilms and deposition on stone, paper and metal surfaces.

Coatings based on metallic and/or inorganic nanoparticles were prepared by sol-gel process and via supercritical $\mathrm{CO}_{2}$ in order to achieve manufacturing processes with minimum energy consumption and the least polluting.

The obtained materials were tested both in terms of antibacterial properties, as well as structurally (FTIR, XRD) and morphologically (SEM, TEM).

Acknowledgements: This work was supported by a grant of the Romanian Ministry of Research and Innovation, CCCDI-UEFISCDI, project number PN-III-P1-1.2-PCCDI-2017-0428, contract 40PCCDI/2018, within PNCDI III and by Romanian Ministry of Research and Innovation -MCI through INCDCP ICECHIM Bucharest 2019-2022 Core Program PN. 19.23-Chem-Ergent, Project No. 19.23.02.01.

(C) 2019 by the authors. Licensee MDPI, Basel, Switzerland. This article is an open access article distributed under the terms and conditions of the Creative Commons Attribution (CC BY) license (http://creativecommons.org/licenses/by/4.0/). 